\title{
Villes et urbanisation en Égypte
}

Éric DENIS (dir.), Villes et urbanisation des provinces égyptiennes. Vers l'écoumènopolis? Le Caire, Centre d'études et de documentation économiques et juridiques, et Paris, Karthala, 2007, 439 p.

\section{Vincent Martignon}

\section{OpenEdition \\ Journals}

Édition électronique

URL : http://journals.openedition.org/transcontinentales/966

DOI : 10.4000/transcontinentales.966

ISBN : 978-2-7351-1563-1

ISSN : 1775-397X

Éditeur

Editions de la maison des sciences de l'homme

\section{Édition imprimée}

Date de publication : 31 décembre 2007

Pagination : 154-156

ISBN : 978-2-200-92397-6

ISSN : 1950-1684

\section{Référence électronique}

Vincent Martignon, «Villes et urbanisation en Égypte », Transcontinentales [En ligne], 5 | 2007,

document 13, mis en ligne le 15 avril 2011, consulté le 25 septembre 2020. URL : http://

journals.openedition.org/transcontinentales/966 ; DOI : https://doi.org/10.4000/transcontinentales. 966 
qu'elle est devenue centrale aujourd'hui dans le contexte de la Moudawana, code du statut personnel et de la famille. Les auteurs analysent comment cette évolution a engagé une double extériorisation des féministes des scènes politique et sociale, alors même que "l'inscription de la question féminine dans le champ de la légitimité religieuse consolide en retour l'autorité du souverain dans ce domaine». Extériorisation de la scène politique d'une part, car si les féministes reconnaissent que "l'égalité politique leur est aujourd'hui effectivement concédée», le choix de l'engagement associatif les met dans le même temps en retrait du champ politique d'autant que ces associations ont tendance à "dépolitiser les problèmes». Extériorisation de la scène sociale d'autre part, car ces associations, en prenant le risque de s'attaquer au statut de la famille et des femmes en leur sein, prennent aussi celui de remettre en cause l'un des fondements majeurs des sociabilités marocaines.

L'exemple égyptien est également abordé dans sa dimension historique, d'autant plus importante ici que ce pays a connu dès les années 1920 des mouvements de revendications féminines. Dès ces années-là, réformisme et modernisme n'ont cessé de promouvoir une même orthodoxie valorisant «une réduction de la diversité des interprétations, de la coutume et du local». Les auteurs rappellent pourtant que, dans ce contexte comme ailleurs, les travaux en histoire des femmes montrent qu'une "attention accrue à la réalité des femmes, toutes catégories sociales confondues», révèle la part qu'elles ont toujours prise en tant "qu'acteurs de la vie économique, par leur travail comme par le contrôle de leurs patrimoines». En revanche, retraçant les moments forts de l'histoire politique contemporaine, les auteurs analysent les changements intervenus depuis les années 1970 comme empreints des rapports de pouvoir propres à la domination masculine : en 1976, l'inscription de la sharî'a comme principale source de droit rappelle avec force que la famille est le principal enjeu des confrontations. Dans ce contexte où l'influence des islamistes se renforce sur la société égyptienne, les auteurs analysent les débats dans lesquels s'impliquent certaines féministes, notamment à propos de l'excision et du voile.

En Jordanie, enfin, les auteurs analysent le contraste entre l'activisme de la famille royale et des plus hautes sphères de l'État en matière de réforme de la condition féminine et la réalité vécue par la majorité des femmes, celle du contrôle patriarcal d'une société tribale. Ici, comme dans les autres contextes nationaux étudiés, une analyse complexe de ces sociétés suppose de comprendre comment s'articulent ou se heurtent «la retraditionalisation et les poussées conservatrices avec l'ouverture au monde», la diversification des conduites, des pratiques et des aspirations des femmes et des hommes.

Hélène Guetat-Bernard, MCF, Université Toulouse-Le Mirail, laboratoire Dynamiques rurales

\section{Villes et urbanisation en Égypte}

\section{Éric DenIs (dir.),}

Villes et urbanisation des provinces égyptiennes. Vers l'écoumènopolis? Le Caire, Centre d'études

et de documentation économiques et juridiques, et Paris, Karthala, 2007, 439 p.

Réunissant treize contributions, l'ouvrage dirigé par Éric Denis met fin au mythe d'une Égypte contemporaine rurale et dominée par la mégapole cairote. Les 
auteurs y soutiennent la thèse d'un pays très urbanisé et davantage polycentrique qu'on ne l'admet habituellement. S'adressant à un public averti, ils analysent les différentes modalités de la croissance urbaine dans leur complexité et leurs effets sur les sociétés locales.

Les articles de la première partie mettent en lumière les dynamiques de croissance qui animent les villes et la «ruralopolis», non reconnue comme domaine urbain par l'État et résultant du mouvement massif d'urbanisation des campagnes. Ainsi, un phénomène massif $\mathrm{d}^{\prime}$ «urbanisation par le bas», entretenu par un ensemble d'acteurs informels (É. Denis), dépasse le cadre de la définition légale de l'urbanisation (É. Denis et F. MoriconiÉbrard). L'indifférence étatique vis-à-vis de ces nouvelles formes de croissance urbaine entraîne la formation de vastes secteurs sous-équipés, contribuant à la formation d'agglomérations "sans qualité urbaine» (I. Yusef et É. Denis). $\mathrm{C}^{\prime}$ est dans ces zones que se développent des pratiques innovantes en termes de solidarité et de régulation sociale. De même, l'évolution des anciens "villages urbains» s'accompagne de recompositions sociospatiales, comme en témoignent la monographie du bourg de Mahallat Rûh (Tantâ, delta du Nil) et l'analyse de la contribution des réseaux marchands au développement économique et au changement social dans les périphéries des grandes villes (T. Dunon, P. Tastevin). Pourtant, si l'on se fie au maintien de la population dans les villes secondaires et dans les bourgs qui enregistrent aujourd'hui les taux de croissance les plus élevés, les capitales régionales semblent moins attractives que par le passé (K. Yousfi et É. Denis).

La seconde partie commence par une analyse du processus de recomposition sociospatiale affectant Mansurâ (située dans le delta du Nil), troisième ville du pays par son nombre d'habitants, qui revendique le statut de métropole régionale. Elle permet à $\mathrm{D}$. Pagès de préciser la place des villes secondaires dans le système urbain égyptien et plus largement dans le système Monde. Or, comme le montre l'analyse des dynamiques identitaires dans le cadre des grands projets conduits dans les villes du canal de Suez (F. Bruyas), l'arrivée d'acteurs extérieurs peut non seulement modifier le rayonnement de ces villes dans le système urbain régional, mais aussi bouleverser leur identité et perturber les systèmes sociaux locaux. Cela n'empêche qu'à l'échelle locale, l'identité d'une ville peut être revalorisée par des projets incitant à la redécouverte d'un patrimoine et d'une histoire oubliés (D. Harre-Rogers). Dans les zones touristiques de Haute-Égypte, il est toutefois indéniable qu'un écart apparaît entre le développement local dû au tourisme et les conditions de vie des habitants. Cet écart pose la double question de la valorisation de sites en tant que ressource, et de la redistribution des revenus du tourisme (S. Gamblin). Sur un plan davantage politique, la participation des habitants doit son dynamisme aux intermédiaires locaux qui mobilisent l'électorat et l'orientent dans son vote. Pour parvenir à leurs fins, ces figures locales cherchent le soutien des leurs et s'appuient sur les systèmes de solidarité en place (N. 'Abd al-Ghaffâr). Les liens sociaux, s'ils peuvent être instrumentalisés à des fins électorales, semblent également former un cadre permettant la préservation des structures sociales. Ainsi, à Balyanâ, la prégnance de ces liens sociaux et le rapport des habitants à la terre ont permis aux structures sociales de perdurer malgré les grands mouvements migratoires qui ont eu 
pour effet de redistribuer localement les richesses, mettant ainsi en péril l'équilibre social en place (C. Miller). Cela n'empêche que, dans ces agglomérations de province en pleine croissance, les habitants élaborent de nouvelles manières de faire société, c'est en tout cas ce que montre F. Colonna dans sa contribution qui laisse la parole aux diplômés installés en province.

En fin de compte, c'est le tableau d'une Égypte souvent ignorée de la communauté scientifique qui nous est offert dans ce portrait des provinces égyp- tiennes et des dynamiques sociospatiales qui les animent. La dimension interdisciplinaire de l'ouvrage et la diversité des cas étudiés sont autant d'éléments qui ajoutent à la richesse des analyses qui y sont proposées.

Vincent Martignon, UMS 2555 Centre français d'archéologie et sciences sociales de Sanaa (CEFAS) / Université de Tours / UMR 6173 Centre interdisciplinaire Cités, Territoires, Environnement et Sociétés (CITERES), Équipe Monde arabe et Méditerranée (EMAM) 